ISSN: $1130-2887$

\title{
LA UNIÓN EUROPEA ANTE CUBA Y COLOMBIA: DE BUENAS INTENCIONES Y ALTAS ESPERANZAS A NOTABLES CONTRADICCIONES Y GRANDES FRUSTRACIONES ${ }^{1}$
}

\author{
The European Union facing Cuba and Colombia: from good \\ intentions and high hopes to notable contradictions and great \\ frustrations
}

Joaquín Roy

Catedrático «Jean Monnet» de Relaciones Internacionales, Director del Centro de la Unión Europea e Investigador Senior del Centro Norte-Sur de la Universidad de Miami

凶jroy@miami.edu

BIBLID [1130-2887 (2002) 31, 33-61]

Fecha de recepción: mayo de 2002

Fecha de aceptación y versión final: julio de 2002

RESUMEN: El autor generaliza, a partir del caso colombiano y cubano, las dificultades y contradicciones de la política exterior común europea, salvo cuando sus acciones políticas se dirigen hacia América Latina, y cuando el eje de una decisión está orientada hacia una postura errónea de Estados Unidos, especialmente si es perjudicial para los intereses colectivos de la Unión Europea y/o de alguno de los Estados miembros. A su vez, bajo el marco de las relaciones internacionales, describe los retos políticos a los que se enfrentan estos países: transición y consolidación de la democracia, respectivamente.

Palabras clave: democracia, proceso de paz, posición común, Plan Colombia, Ley Helms-Burton.

1. Para la elaboración de este trabajo, numerosos funcionarios de diversos gobiernos europeos y varios miembros del personal de la Comisión Europea han contribuido con comentarios y documentación. Todos ellos han preferido permanecer anónimos y no pueden ser señalados como responsables del tono o contenido de los comentarios, que son de la exclusiva competencia del autor. 
ABSTRACT: The author generalizes, from the cases of Colombia and Cuba, the difficulties and contradictions of Europe's common foreign policy, except when its political actions are directed toward Latin America and when the axis of a decision is oriented towards an erroneous posture of the United States, especially if it is prejudicial for the collective interests of the European Union and/or some of its member States. At the same time, within a framework of international relations, the paper describes the political challenges that these countries face: democratic transition and consolidation, respectively.

Key words: democracy, Peace Process, Common Position, Plan Colombia, HelmsBurton Law.

\section{HACIA UNA POLÍTICA EXTERIOR COMÚN}

Durante la Presidencia española de la Unión Europea (UE), en el primer semestre de 2002, dos líneas de decisiones (parte de una estrategia de larga duración) de la UE o sus Estados miembros con respecto a dos países de América Latina (Cuba y Colombia) revelan no solamente la actitud europea hacia el continente americano, sino el perfil de su política exterior incipiente.

En la sesión de la Comisión de Derechos Humanos de las Organización de las Naciones Unidas, celebrada en Ginebra en abril de 2002, los Estados miembros de la UE votaron en bloque por la resolución que criticaba el balance de Cuba en ese terreno y recomendaba el envío de una inspección. No solamente esta decisión concordaba con la moción presentada esta vez por un grupo de países latinoamericanos, sino que contó también con el respaldo de los países que son candidatos a ingresar en la UE.

Conviene anotar dos hechos poco conocidos. El primero es que los países candidatos no tienen legalmente que votar en sintonía con los miembros, pero se supone que en el aprendizaje deben adherirse a estas acciones en los foros internacionales, tal como han venido haciendo a lo largo de la última década. El segundo detalle es que antes de la votación había rumores, bien fundados, de que Bélgica quería abstenerse, a pesar de que la resolución era esa vez muy descafeinada (pues aludía a las dificultades impuestas por el embargo), e incluso reconocía una mejora en la conducta social de Cuba. Al final, se impuso el consenso. La consecución de esta aparente muestra de política exterior coordinada no es una obligación legal, pero la UE intenta formar un frente común a toda costa.

En otro contexto, la UE emitió el 2 de mayo una declaración que incluía en sus listas de terroristas a las Autodefensas Unidas de Colombia (AUC), los paramilitares que completan el trío violento que se disputa con el gobierno acosado el control del territorio, pero no mencionó a los otros dos, el Ejército de Liberación Nacional (ELN), y sobre todo a las Fuerzas Armadas de Colombia (FARC), para gran escándalo colombiano. Este hecho contrasta con la declaración de la Presidencia española de la UE en la que calificaba las acciones de las FARC como «terroristas», a raíz del secuestro de la candidata presidencial Ingrid Betancourt. Tal declaración revelaba que no se había conseguido el consenso 
necesario para ser adoptada como una resolución conjunta del propio Consejo de la UE, lo que se evidenciaba con la lista incompleta.

Al parecer, Francia (por motivos de seguir teniendo un punto de apoyo para conseguir la liberación de Betancourt, quien goza de doble nacionalidad) y Suecia (que quería mantener la puerta de la negociación abierta) se opusieron a la inclusión porque daría pie a los sectores que apostarían por la guerra total, lo que haría desaparecer todas las posibilidades de reanudar el Proceso de Paz. Ambos países negaban haberse opuesto. Todo esto sucedía justamente mientras las FARC retenían centenares de secuestrados, en la víspera de la mayor masacre de civiles (muchos de ellos niños) de los últimos meses. Lo anterior evidencia la tenacidad para lograr la coherencia de la UE en política exterior. Por otro lado, se constatan también las dificultades y contradicciones.

En el caso de Cuba, obsérvese que el registro de las votaciones en las Naciones Unidas, desde 1996, año de aprobación de la lamentable Ley Helms-Burton, revela que los Estados europeos miembros de la Comisión han mantenido una actitud de bloque. La votación de Ginebra no cambia ningún aspecto crucial, sino que confirma una pauta. Mientras la Asamblea General de la ONU ha estado condenando el embargo de Estados Unidos contra Cuba desde tiempo inmemorial, hasta el extremo de que Washington ha quedado totalmente aislado, solamente secundado por Tel-Aviv, los debates en Ginebra con respecto a la violación de los Derechos Humanos en Cuba han sido la contraparte. Desde que en 1992 se nombró a un representante especial para que elaborara un informe, los resultados de las votaciones han sido aleccionadores, muy especialmente desde la aprobación de la Ley Helms-Burton en marzo de 1996 y la puesta en funcionamiento de la ley antídoto contra esta legislación extraterritorial. Europa siempre ha votado contra el embargo norteamericano y contra la violación de los derechos humanos en Cuba.

En el caso de Colombia, el balance superficial parece ser aquejado de una mayor incoherencia, con lo que se pone en evidencia las falta de acuerdo básico entre los actores fundamentales. Tras la elección de Álvaro Uribe como presidente de Colombia el 26 de mayo de 2002, diversos protagonistas de la UE seguían refiriéndose a las guerrillas como «grupos armados» o «insurgentes», y la etiqueta de «terroristas» desaparecía de las comunicaciones oficiales. Sin embargo, la impresión provisional no concuerda exactamente con las realidades subyacentes que conviene examinar con un mayor detalle. También conviene ponderar los resultados de las expectativas en casa caso y su potencial cumplimiento.

\section{LA UNIÓN EUROPEA Y COLOMBIA²}

\section{II.1. De buenas intenciones a grandes frustraciones}

Desde el anuncio del original Plan Colombia, la actitud europea para contribuir a solucionar la crisis de endémica violencia osciló desde una posición de alarma a

2. Esta parte del artículo está basada en un trabajo presentado en la conferencia «¿Existe una política de la Unión Europea para Colombia?», organizada por el Institut d'Hautes Études de l'Amerique 
una de esperanza (cuando no de grandes expectativas), y finalmente desembocó en un sentimiento de frustración y realismo impotentes, sin abandonar el compromiso de contribución a la consecución de la paz. En las primeras etapas, una cautelosa actitud dominaba la percepción europea sobre un plan que se consideraba inspirado por los Estados Unidos, y que se trataba de vender como un producto genuinamente colombiano3. Se rechazaba explícitamente el Plan Colombia y se apostaba por el Proceso de Paz.

«Una contribución virtual a un plan virtual de paz», en palabras anónimas de un alto funcionario de la UE, era la más fiel ilustración de la posición europea. Por una parte, en Bruselas se temía que el proceso no contaba con el eficaz compromiso de las partes en litigio. Se sospechaba tanto de la debilidad negociadora del gobierno como de la reticencia de la guerrilla de las FARC y de los paramilitares a enterrar las armas. Por si acaso, los europeos se mostraban desconfiados, con temor de pagar los platos rotos una vez se produjera la escalada de las hostilidades y Washington solicitara financiar la reconstrucción de los daños.

En general, «buenas intenciones» (una expresión clásica de los expertos en ayuda al desarrollo) sería la etiqueta que encajaría en la implicación europea en Colombia, para reflejar la sincera voluntad y las limitaciones. Este caso paradigmático revelaba una endémica falta de coordinación de la ayuda internacional, la carencia del llamado «factor de absorción» local (multiplicado al insistir los donantes en canalizar la ayuda nacional a través de Organizaciones no Gubernamentales [ONG's] carentes de capacidad de acción y necesitadas de una seguridad mínima), y la contradicción entre los programas de la ayuda que se ofrece y la que se necesita. Se presentaba un panorama esperpéntico entre el gobierno colombiano que pedía una ayuda financiera y los europeos que respondían con los planes de anterior diseño.

Sin embargo, «a caballo regalado no le mires el dentado», parecía decir castizamente el gobierno colombiano ante el ofrecimiento de la ayuda internacional que en el caso europeo ascendía a unos $\$ 300$ millones en fondos de la UE, y que superaba los $\$ 1.000$

Latine de la Universidad de París (Sorbonne) los días 19-20 de marzo de 2002. Extiendo mi agradecimiento a Jean Michel Blanquer por la invitación y a Ambler H. Moss, director del Centro Norte-Sur, y a Max Manwaring, del U.S. Army War College, por el apoyo en el diseño de la investigación. El trabajo refleja el contenido de otro anterior presentado en la conferencia Implementing Plan Colombia: Strategic and Operational Dimensions for the U.S. Military, organizada en Miami, Florida, entre el 31 de enero y el 2 de febrero de 2001, por el U.S. Army War College y el North-South Center de la Universidad de Miami. El contenido de esta parte del trabajo refleja parcialmente fragmentos de los siguientes artículos: European Union perceptions of Plan Colombia: A Virtual Contribution to a Virtual War and Peace Plan? Carlisle, Pennsylvania: U.S. Army War College/North-South Center, 2001; Europa y el Plan Colombia: el doble discurso de la UE, Política Exterior, 2001, vol. XV, n. ${ }^{\circ} 83$, pp. 31-42; La asistencia europea a Colombia: ¿una contribución virtual a un plan virtual de paz? En Colombia Internacional. Universidad de Los Andes, 2001.

3. Para una evolución completa del conflicto y las ideas para resolverlo, consúltese la página digital de la Fundación Ideas para la Paz: http://www.ideaspaz.org/. 
millones en contribución global. Grandes esperanzas dominaban las declaraciones desde el 30 de abril de 2001, cuando en Bruselas se anunciaba a bombo y platillo la disposición de la ayuda mundial al Proceso de Paz. Al mismo tiempo, el propio gobierno colombiano certificaba de esa manera haber llegado a cumplir los objetivos del Plan Colombia (más de $\$ 7.000$ millones; $\$ 4.000$ debían salir de fondos colombianos), en un evidente ejercicio de contradicción semántica, cuando no de fondo. Como resultaría evidente con la ruptura del 20 de febrero de 2002, era como un cuento de la lechera con ribetes trágicos.

Pero, a la vista del notable capital diplomático invertido en el esfuerzo, no hubo desfallecimiento. Europa no solamente se había implicado en el Proceso de Paz con las FARC, sino que se había convertido en un protagonista insustituible en el procedimiento paralelo con el ELN. Todo comenzó a desplomarse a principios de 2002. A mitad de enero el controvertido acuerdo entre el gobierno colombiano y las FARC acerca de la «zona de despeje» se abocaba a un desastre. Bajo la amenaza del ultimátum presentado por el presidente Pastrana y la impredecible reacción de la guerrilla colombiana, la situación podía degenerar en una guerra abierta. La UE y numerosos diplomáticos europeos temían el fin de su labor de mediación hacia una paz duradera, o por lo menos en apoyo de la extensión de una tregua parcial y limitada en tiempo y espacio. La declaración de la UE, el 10 de enero, fue categórica y mostró «profunda preocupación» por la situación, y reiteró el apoyo a los esfuerzos de Pastrana, como el representante legítimo de la voluntad democrática y del pueblo colombiano. Al mismo tiempo, exigía a las FARC que tradujeran con hechos sus deseos de paz.

Cuando el gobierno y las guerrillas decidieron seguir las negociaciones bajo la presión diplomática, la UE confirmó su compromiso de financiación de proyectos en el santuario controlado por las guerrillas. El anuncio de un nuevo calendario de negociaciones que habría desembocado en un cese de violencia definitivo fue el último premio de consolación para los esfuerzos europeos.

Tras la decisión de Pastrana el 20 de febrero de terminar el proceso ante el secuestro del senador Eduardo Gechem Turbay, la UE resolvió respaldar y entender la decisión. Cuando se produjo el secuestro de la candidata presidencial Ingrid Betancourt, el lenguaje de la Presidencia de la UE insertó por primera vez la palabra «terrorismo», usada novedosamente por el propio Pastrana para referirse a las FARC para calificar sus acciones. De alguna manera, se cerraba el círculo del lenguaje usado por Washington y Bogotá que había comenzado con la reconversión de una lucha «contrainsurgencia» y el problema del narcotráfico, para tratarla como una estrategia contra una nueva amenaza: «narcoterrorismo», redefinido tras el 11 de septiembre como «terrorismo internacional».

\section{II.2. La implicación europea en la crisis colombiana}

Una revisión más detallada de los hechos que llevaron a la ruptura revela que la situación se había oscurecido ostensiblemente y se había convertido en insostenible 
para el gobierno colombiano, mientras los participantes internacionales parecían reprimir sus actitudes a la espera de ver quién rompía la baraja primero (para usar una expresión popular frecuentemente empleada en círculos diplomáticos). Ése no podía ser otro que el presidente colombiano, a la vista de que los procedimientos de los demás habían pasado la línea permisible o habían violado los acuerdos explícitos.

La opinión en los Estados Unidos ya había oscilado hacia una posición más dura, tal como reflejaban ex funcionarios de Clinton en columnas publicadas en esos cruciales momentos ${ }^{4}$. Al mismo tiempo, los editoriales de diarios influyentes apoyaban los esfuerzos de Bush para convertir la ayuda de los Estados Unidos en más eficaz 5 . La opinión de la elite política norteamericana se había inclinado significativamente hacia la idea que se requería una participación más directa en el conflicto colombiano, con el consiguiente soslayo de las negociaciones de paz y como aparente resultado de los ataques del 11 de septiembre. «Terrorismo» era ya la palabra clave que se usaba, como sustituto de la «estrategia de contrainsurgencia» y del «control del narcotráfico», que constituían el marco original que se había vendido al Congreso para justificar la bondad del Plan Colombia. El gobierno colombiano comenzó cabildear con energía para usar los recursos de la lucha contra el narcotráfico en las actividades contrainsurgencia, con lo cual equiparaba la lucha contra las FARC a la ofensiva militar contra Al Qaeda . En las declaraciones públicas, la Casa Blanca limitaba su posición a los parámetros hilvanados por el Congreso en la lucha contra las drogas7. En consecuencia, los comentarios en España supieron capturar la naturaleza de las noticias ${ }^{8}$, mientras los medios británicos eran ejemplo de la opinión europea ${ }^{9}$, al tiempo que sus líderes mostraban comprensión y apoyo para Pastrana, en la que se fijaba el tono de futuras acciones y la actitud general ante la crisis ${ }^{10}$.

Como reacción al secuestro de la candidata presidencial Ingrid Betancourt, la Presidencia española de la UE emitió una declaración en la que se condenaba la acción y

4. Peter Romero. Save Colombia. The Washington Post, 20 de febrero de 2002, p. A15.

5. Colombia Strikes Back Attacking Terrorist Rebels. The Miami Herald, 22 de febrero de 2002; Help for Colombia. The Washington Post, 24 de febrero de 2002, p. B06.

6. AFP. Ofensiva de las FARC se acerca a Bogotá. Diario las Américas, 28 de febrero de 2002.

7. EFE. Bush le dice «no» a Pastrana. El Nuevo Herald, 28 de febrero de 2002, p. 1A.

8. Francisco Santos. Más de lo mismo. El País, 22 de febrero de 2002; La hora de la guerra, El País, 22 de febrero de 2002; El proceso de paz en Colombia queda en el aire tras el secuestro de un senador, El País, 21 febrero 2002; Pilar LOZANo. Pastrana iza la bandera colombiana en el terreno recuperado a la guerrilla. El País, 24 de febrero de 2002; Pilar LOZANO. Indignación por las víctimas de los bombardeos del Ejército. El País, 24 de febrero de 2002; Pilar LOZANO. El Ejército de Colombia reconquista la base de las FARC en la zona neutral. El País, 23 de febrero de 2002.

9. Outrage at Colombian kidnap. BBC News, 26 de febrero de 2002; Martin HodGSON. Colombian army takes back rebel capital. The Guardian, 25 de febrero de 2002; Martin HodGSON. Colombia abandons peace effort. The Christian Science Monitor, 25 de febrero de 2002; Politician seized in Colombia. Belfast Telegraph-Financial Times, 25 de febrero de 2002.

10. Declaration by the Presidency on behalf of the European Union on the breakdown of the Peace Process in Colombia (Brussels, 22 de febrero de 2002). 
demandada su liberación. Expresando solidaridad con la familia, la declaración calificaba este tipo de actividades como «terrorismo» ${ }^{11}$. Se trataba, por lo tanto, de un cambio drástico de tono, convenientemente detectado por las autoridades colombianas y los observadores internacionales, en lo que respecta a las acciones violentas cometidas por las FARC. Con anterioridad se habían empleado etiquetas más suaves como «combatientes». El cambio (o el retraso en usar el calificativo de «terrorismo») estaba justificado por el propio gobierno colombiano: los representantes de la UE y los gobiernos europeos se habían autolimitado en este sentido a la vista de que el presidente colombiano mantenía la vía de la negociación ${ }^{12}$.

En consecuencia, al tiempo que se mantendría la promesa de apoyar a Colombia, los programas de la UE deberían ser reevaluados de acuerdo con los nuevos parámetros de riesgo y a la espera de lo que solicitaran las nuevas autoridades colombianas como resultado de las elecciones presidenciales ${ }^{13}$. De momento (y para un largo plazo, según los cálculos más pesimistas), la contribución europea parecía estar relegada a continuarse desde una distancia más prudente. No solamente el espíritu del original Plan Colombia parecía tomar un rumbo de mayor confrontación, sino que las esperanzas asociadas con el Proceso de Paz se habían desvanecido. De estar presidida por buenas intenciones, la actitud europea había cambiado a estar dominada por una gran frustración. A pesar de todo, en cualquier variante de reanudación de negociaciones, la implicación europea es insustituible, y por lo tanto convendría hacer una completa revisión y repaso de las percepciones europeas hasta el momento.

\section{II.3. Rechazando el Plan Colombia, apostando por el Proceso de Paz}

En mitad de enero de 2002, el controvertido acuerdo entre el gobierno colombiano y las FARC para la extensión del territorio como santuario estaba al borde del colapso. Bajo la amenaza del ultimátum presidencial y la reacción impredecible de las guerrillas, la situación inestable estaba en peligro de degenerar en una guerra abierta ${ }^{14}$. Tal como los acontecimientos posteriores confirmarían, la actitud de los Estados Unidos había comenzado a cambiar ${ }^{15}$. Los funcionarios europeos temían el final de sus esfuerzos en

11. Declaración de la Presidencia de la Unión Europea sobre el secuestro de la candidata presidencial en Colombia (Madrid, 25 de febrero de 2002).

12. Declaración de José Ignacio Salafranca, miembro de Parlamento Europeo, en la conferencia celebrada en marzo de 2002.

13. Declaraciones de Cándido Rodríguez, jefe de la delegación de la UE en Bogotá, en el curso de la conferencia de París.

14. Como reflejo de la percepción europea: Juan Jesús AzNÁREZ. El Ejército colombiano se rearma para hacer frente a las guerrillas. El País, 18 de enero de 2002.

15. The Washington Post, 14 de enero de 2002, p. A16; Karen De Young. U.S. eyes shift in Colombia policy. The Washington Post, 15 de enero de 2002, p. A01. 
mediar por la paz ${ }^{16}$. Una declaración de la Presidencia de la UE era categórica ${ }^{17}$. Cuando el gobierno y las guerrillas acordaron seguir negociando ${ }^{18}$, la UE confirmó su respaldo ${ }^{19}$. Bruselas emitió una de sus más optimistas declaraciones hasta entonces ${ }^{20}$.

$\mathrm{El}$ anuncio ${ }^{21}$ del nuevo calendario de conversaciones que debían traducirse en un cese de hostilidades revelaba el papel crucial de los representantes europeos22. Aunque el armisticio se alejó del panorama, ya los gobiernos europeos y la propia Comisión de la UE habían invertido considerable energía diplomática, apoyo político y financiación para proyectos para reforzar el Proceso de Paz. En consecuencia, el fracaso de las negociaciones era un golpe considerable. Establecida el 9 de marzo de 2001, en Los Pozos (Caquetá), la Mesa de Diálogos de 26 Países Amigos creó una Comisión Facilitadora que se debía reunir cada seis meses, compuesta de 10 países (Canadá, Cuba, España, Francia, Italia, México, Noruega, Suecia, Suiza y Venezuela). Una confrontación directa entre el Ejército colombiano y las FARC hubiera hecho peligrar el papel sistemático de los gobiernos europeos en las negociaciones con el ELN. Este peligro sufrió una magnificación tras la ruptura del 20 de febrero.

El gobierno colombiano se sintió aliviado por el hecho de que la asistencia económica y social ha procedido principalmente de Europa. La satisfacción en Europa y Colombia era visible cuando en las últimas horas del domingo 20 de enero, minutos antes de vencerse el plazo, el gobierno colombiano y las FARC confirmaron (tal como avanzaban los medios de comunicación ${ }^{23}$ un nuevo acuerdo para reanudar las negociaciones. A pesar de la fragilidad de los acuerdos, el papel de la comunidad internacional, y muy especialmente los esfuerzos de los diplomáticos europeos, se consideró como irremplazable ${ }^{24}$. Una declaración de Bruselas era taxativa al efecto ${ }^{25}$.

16. Principalmente del Grupo de Países Amigos (España, Francia, Italia, Suecia, Suiza, Noruega, México, Cuba, Canadá y Venezuela).

17. Madrid, 10 de enero de 2002.

18. Fernando CEPEDA. Facilitación internacional. El Tiempo, 15 de enero de 2002; El papel de la comunidad internacional, Editorial. El Tiempo, 21 de enero de 2002.

19. AFP. La UE no excluye financiar proyectos en zona de las FARC, Diario las Américas, 16 de enero de 2002, AFP. Unión Europea y España apoyan. Diario las Américas, 13 de enero de 2002, p. 3 A.

20. Declaration by the Presidency on behalf of the European Union on the Schedule Agreement between the Government of Colombia and the FARC-EP (Brussels, 24 de enero de 2002).

21. Texto completo del acuerdo: http://eltiempo.terra.com.co/21-01-2002/prip159999.html; de fuentes del gobierno colombiano: http://www.presidencia.gov.co/webpresi/noticias/2002/enero/infenot.htm.

22. El Tiempo, 21 enero 2002; Gonzalo GuILLÉn. Firmarán la tregua en abril. El Nuevo Herald, 21 de enero de 2002, p. 1A; Nancy SAN MARTín. Colombia peace process revived. The Miami Herald, 21 de enero de 2002, p. 3 A.

23. Sol Gómez Giraldo y María Luisa Murillo. Día de mucha expectativa. El Tiempo, 20 de enero de 2002.

24. AFP. Comunidad internacional: papel clave en futuros diálogos. Diario las Américas, 22 de enero de 2002, p. 3 A.

25. 16 de enero de 2002 . 
El acuerdo, y el proceso que lo canalizó, no fue universalmente asumido en Colombia, donde una mayoría de la población y los principales candidatos a suceder a Pastrana han sido críticos de una política que perciben que ha dado ventajas a las FARC sin recibir nada a cambio ${ }^{26}$. En los medios de comunicación colombianos, el papel de la comunidad internacional fue cuestionado por sus limitaciones, contradicciones y dependencia de los intereses nacionales ${ }^{27}$. Diversos observadores denunciaban la limitación de la promesa de las FARC para terminar los secuestros colectivos («pesca milagrosa»), y la continuación con los individuales para conseguir rescate ${ }^{28}$. El clima político no mejoró, los secuestros y asesinatos continuaron, la destrucción de la infraestructura llegó a la ser la rutina diaria, y las amenazas respecto a la violencia urbana se convirtieron en realidad 29 .

\section{II.4. Palabras, cifras y hechos}

El 30 de abril de 2001, Chris Patten, comisario europeo de Relaciones Exteriores, con gran satisfacción había anunciado en Bruselas, ante un impresionante conjunto de donantes internacionales, que la UE confirmaba la contribución de unos $\$ 300$ millones para el Proceso de Paz en Colombia ${ }^{30}$. Simultáneamente, el presidente colombiano Andrés Pastrana, recién llegado de Noruega y Alemania, declaraba en Bogotá que el famoso y controvertido Plan Colombia estaba financieramente cubierto ${ }^{31}$. En adición a los $\$ 4.000$ millones procedentes de fondos colombianos, la oferta europea completaba la cifra de $\$ 3.500 .000$ millones en fondos procedentes del exterior para redondear un total de $\$ 7.500 .000$ millones destinados a transformar a Colombia, de ser percibida

26. Reflejando la opinión europea: Juan Jesús AzNÁrez. ¡Ojalá Pastrana hubiera pedido ayuda militar a EE.UU.!, El País, 19 de enero de 2002; para un resumen de las opiniones colombianas, véase el informe de El Tiempo, 21 de enero de 2002.

27. El Tiempo, 8 febrero 2002: Reflexiones en la encrucijada VI, Editorial: La otra pata de la mesa; SOCORRO RAMÍREZ, Mayor claridad y prontos resultados. La presencia internacional.

28. Para una crítica de un miembro de Parlamento Europeo, véase: Emilio MENÉNDEZ DEL VALLE. ¿Adónde vas, Colombia? El País, agosto 2001.

29. Gerardo REYES. Inminente la guerra urbana en Bogotá. El Nuevo Herald, 3 febrero 2002, p. $1 \mathrm{~A}$.

30. Colombia: an international commitment to peace, Brussels, 30 de abril de 2001; ANCOL. Palabras del comisionado Chris PATTEN ante el Grupo de Apoyo, 30 abril 2001; Colombia: una contribución europea para la paz. $A B C, 1$ mayo 2001; ANCOL. Discurso del alto comisionado ante comunidad internacional, Bruselas, 30 abril 2001: http://www.presidencia.gov.co/webpresi/noticias/ 2001/abril/infenot.htm. Website de la UE: Multiannual Support Programme for Colombia, Brussels, 28 de octubre de 2000: http://europa.eu.int/comm/external_relations/colombia/intro/ip_00_1184.htm.

31. ANCOL. El Plan Colombia ya es una realidad: Pastrana, 1 mayo 2001. Para un detallado presupuesto del gobierno colombiano: http://herramientasparalapaz.gov.co/index.asp?vinculos $=1 \&$ noticialD $=243 \&$ programa $=0$. 
como una sociedad en desintegración, y dominada por la guerrilla y el narcotráfico, en una sólida democracia y una robusta economía.

Este impresionante ejemplo de unidad demostrado por veintisiete países y diez organizaciones internacionales, que fueron convocados por el Banco Interamericano de Desarrollo (BID) en la capital de la UE, era como un sueño de cooperación mundial convertido en realidad. Aunque en rigor la UE solamente contribuía unos \$100 millones de su propio presupuesto, el financiamiento procede de todos los confines del mundo, como producto de un programa de maratón telefónica o televisiva. Un año antes, los Estados Unidos habían prometido \$1.300 millones, 250 de los cuales debían ser destinados a programas sociales e institucionales. España lideró la iniciativa europea con una oferta de $\$ 100$ millones. Japón donaría $\$ 70$ millones para proyectos de irrigación, la ONU comprometió \$131 millones de sus programas de protección de la infancia, el FMI y la banca internacional proporcionarían otros $\$ 1.000 .000$ millones, y $\$ 300$ millones fueron reservados por el Banco Mundial, el BID y la Comunidad Andina. Suiza donó \$15 millones. Incluso Portugal se comprometió a donar \$300.00032. Con posterioridad, como respuesta a la presión internacional, la Casa Blanca prometió aportar $\$ 800$ millones adicionales destinados a la llamada Iniciativa Regional de los Andes (IRA) ${ }^{33}$, con inmediato beneficio para Colombia ${ }^{34}$.

32. Juan Carlos IragorRI. US $\$ 304$ millones para Colombia. El Tiempo, 1 de mayo de 2001; Hoy se concreta apoyo europeo a la paz, El Espectador, 1 de mayo de 2001; AFP. Anuncia la UE \$294 millones de ayuda a Colombia. Diario las Américas, 1 mayo 2001; Alberto SOTILLO. La UE aporta 338 millones. ABC, 1 de mayo de 2001; Gabriela CAÑAS, La UE aportará 60.000 millones al proceso de paz colombiano, El País, 1 de mayo de 2001; Elisa SANTAFÉ. AFP, Colombia completa fondos para la paz. El Nuevo Herald, 1 de mayo de 2001.

33. Comunidad Andina and European Union, Reunión Ministerial entre la Comunidad Andina y la Unión Europea. Comunicado de Prensa Conjunto, Santiago de Chile, 28 de marzo de 2001; http://www.delcol.cec.eu.int/noticias.htm\#andina.

http://europa.eu.int/comm/external_relations/andean/intro/index.htm.

Plan multianual de la ayuda de la UE a Colombia:

http://europa.eu.int/comm/external_relations/colombia/intro/sec_1647_en.htm.

Panorama de las actividades de la UE en Colombia:

http://www.delcol.cec.eu.int/noticias.htm\#ayuda.

Para un panorama de las relaciones entre la UE y Colombia:

http://www.delcol.cec.eu.int/uecolombia.htm http://europa.eu.int/comm/external_relations/colombia/intro/index.htm.

Lista de los proyectos de la UE llevados a cabo por las ONG's europeas en Colombia:

http://www.delcol.cec.eu.int/proyecol.htm.

Para una revisión de las actividades de la UE en Colombia, véase el boletín:

http://www.delcol.cec.eu.int/euronotas/28.pdf, y especialmente el de 2001: http://www.delcol.cec.eu. int/euronotas/27.pdf.

34. Juan Carlos IragorRI. US $\$ 304$ millones para Colombia. El Tiempo, 1 de mayo de 2001; Hoy se concreta apoyo europeo a la paz. El Espectador, 1 de mayo de 2001; AFP, Anuncia la UE \$294 millones de ayuda a Colombia. Diario las Américas, 1 de mayo de 2001; Alberto Sotillo. La UE aporta 338 millones. $A B C, 1$ de mayo de 2001; Gabriela CAÑAS. La UE aportará 60.000 millones al proceso de paz colombiano. El País, 1 de mayo de 2001; Elisa SANTAFÉ. AFP, Colombia completa fondos para la paz. El Nuevo Herald, 1 de mayo de 2001. 


\section{II.5. El Plan Colombia en la perspectiva europea}

La negativa percepción de Europa se convirtió en evidente cuando en agosto de 2000 se escrutaron los detalles de la implicación de los Estados Unidos, con motivo de la visita del presidente Clinton a Cartagena de Indias. Con posterioridad, el análisis comparativo de los esfuerzos de la lucha contra el tráfico de drogas en ausencia de la atención suficiente a los asuntos sociales e institucionales ha impactado todavía más la actitud critica de los observadores europeos ante lo que hasta el momento era de exclusivo dominio de los gobiernos y especialistas.

En cuanto se conocieron los detalles del respaldo de los Estados Unidos, la reacción en Europa podía ser ilustrada como un movimiento de manos y brazos en dos tiempos, como en un ejercicio de gimnasia sueca. En primer lugar, los funcionarios europeos levantaban los brazos y colocaban las manos sobre la cabeza, para expresar un sentimiento de incredulidad y temor. A continuación, se llevaban las manos a los bolsillos para palpar las billeteras y comprobar que estaban en su lugar. Consideraban que se les pedía que pagaran por los gastos adicionales, que eran más caros que los proyectos centrales, como en esas construcciones donde los presupuestos se multiplican en cifras de proporciones descomunales. Parecía que el financiamiento europeo sería necesario cuando el equipo militar se agotara y la última gota de sangre de los colombianos hubiera sido derramada, en expresión dramática de un especialista ${ }^{35}$.

En resumen, los europeos tenían la impresión de que deberían pagar por los daños de una guerra que no habían perpetrado ni habían empeorado. Durante décadas, la implicación de los Estados Unidos en diversas zonas del mundo, muy especialmente en América Latina, se ha comparado con los movimientos de un elefante que desearía pasar desapercibido, pero que se halla anclado al terreno, inclinado a derribar el mástil central de la carpa del circo, con trágicas consecuencias. El Plan Colombia se ajusta a esta percepción.

Sin embargo, se detecta la presencia de un doble discurso que preside la escena entre lo que se pide de Europa, y cómo los europeos responden en público y cómo lo hacen confidencialmente. Los gobiernos europeos revelan que sus análisis están aquejados de un comprensible doble perfil. Por una parte, los gobiernos que mantienen una relación cordial con el gobierno colombiano tienen sumo cuidado de no expresar en público las opiniones alarmantes que usan en privado y en comunicaciones confidenciales.

35. Juan Gabriel ToKATLIAN. Hasta el último gramo de cocaína y el último hombre colombiano. El Tiempo, Bogotá, 28 de agosto de 2000. Véanse también: Joaquín Roy. Hasta el último hombre, el último dólar y el último gramo de cocaína. Diario las Américas, 1 de septiembre de 2000; La Opinión de los Ángeles, 3 de septiembre de 2000; Fins a l'últim home, l'últim dólar i l'últim gram de cocaína. Avui, Barcelona, 5 de septiembre de 2000; Pilar LOZANo. Clinton presenta su plan antidroga en una Colombia dividida. El País, 30 de agosto de 2000; Andrew Reding. Plan Colombia: Un túnel demasiado largo. La Opinión, Los Ángeles, 20 de octubre de 2000; Javier VAlEnZuela. Estados Unidos teme verse envuelto en un largo conflicto en América Latina. El País, 27 de agosto de 2000. 
Consideran la situación como endémica, propia de una sociedad fracturada, y no un simple conflicto entre gobierno y guerrillas como en una película de policías y ladrones que se desarrolla en un escenario tropical. Este doble discurso se aplica también a los comentarios de un aparente acuerdo entre los Estados Unidos y Europa.

En conversaciones confidenciales, los funcionarios europeos tienden a ser más explícitos. Los gobiernos y organizaciones europeas tienen la impresión de que se les pide pagar una factura económica y social, mientras en el otro lado del Atlántico el drama es reducido a un problema de narcotráfico y enfrentamiento militar. Expresando la reacción ante las propuestas de financiamiento, como comentario a una sección del Plan Colombia sobre la contribución de la comunidad internacional ${ }^{36}$, un diplomático español anotó en los borradores de los documentos esta gráfica expresión popular: «Poner la pasta» ${ }^{7}$. En términos más crudos, nunca detectados en los documentos o en declaraciones vaporosas, siempre ha existido la impresión europea de que los colombianos han estado contribuyendo con los muertos, los Estados Unidos suministran el equipo militar y los europeos donarán el dinero para aminorar el coste social y el daño ecológico causado por las otras dos partes. Esta ayuda europea se percibe en diversos círculos de Europa como una especie de remedio en cuanto se termine la ejecución de los planes militares de los Estados Unidos. Este sentimiento, compartido por muchos funcionarios y diplomáticos en oficinas y pasillos de Madrid, París y Bruselas, se refleja también en informes y comentarios independientes con una impresionante coincidencia. Con la cooperación europea, los colombianos deberán «limpiar los destrozos dejados por los norteamericanos» 38 . Este retrato del papel a jugar por la contribución internacional se dramatizó después de la ruptura del 20 de febrero de 2002.

\section{II.6. La necesidad y la dificultad de la ayuda europea}

A pesar del empeoramiento de la situación como resultado de la decisión del 20 de febrero, una vez el contexto de seguridad lo permita, el compromiso europeo no desfallecerá, al menos en los sectores político y humanitario. La presión para participar continuará gracias a una serie de factores. En primer lugar, la contribución europea siempre ha sido bienvenida en América Latina en general, y muy especialmente en crisis como la de Colombia. La participación europea raramente es percibida como un caso «injerencia». Es más, si el ejemplo de Centroamérica sirve de referencia como

36. Los proyectos están detallados en la página de la Presidencia de la República de Colombia: http://www.presidencia.gov.co/plancolo/volumen2/doc1.htm.

37. Véase la confirmación de esta percepción en la entrevista de Chris PATTEN en El Espectador, y el propio artículo del comisario, Colombia: una cita por la paz. El Mundo y El Espectador, 24 de octubre de 2000.

38. Expresión citada por James Petras. El Plan Colombia y sus críticos. El Mundo, 26 de julio de 2000 . 
base de comparación, la participación de la UE, sus Estados miembros, o las ONG's europeas no están sujetas a procedimientos rígidos de justificación de presupuestos y gastos. El emblema azul de las doce estrellas doradas es un signo de excelencia y una garantía, en contraste frecuente con los programas financiados por los Estados Unidos, lo que puede ser interpretado como injusta apreciación de la contribución de numerosas instituciones norteamericanas. Simplemente responde al pago por los errores del pasado. El uso de los servicios europeos tiene todavía un considerable capital político de garantía para el futuro. No es sorprendente, entonces, que numerosas fuentes gubernamentales, centros de reflexión y académicos de los Estados Unidos estén de acuerdo en que Europa es un actor indispensable. En vista de la complejidad de la crisis colombiana, se requiere que sea tratada mediante una multiplicidad de contribuyentes ${ }^{39}$. Apenas se cuestiona el papel central de los actores europeos, sea como UE, o a través de los Estados o las ONG's.

Antes del 11 de septiembre, el papel de Europa hubiera recibido un mayor ímpetu si se hubiera aplicado una política norteamericana más cautelosa una vez la nueva Administración en Washington estaba asentada ${ }^{40}$. Entonces y ahora, una variante más diplomática del Plan Colombia, o alguna de sus partes, podría proporcionar un terreno maniobrable para los esfuerzos europeos, libres de entramparse en un complejo escenario que prima las soluciones militares ${ }^{41}$.

El precedente de la experiencia en Centroamérica todavía ofrece esperanza. Es cierto que el final de la Guerra Fría pudo haber contribuido a la resolución del proceso de paz más que la presión ejercida por los actores europeos en la senda del Proceso de San José. También es cierto que las negociaciones y el final de los sangrientos conflictos no han hecho desaparecer las causas socioeconómicas de las guerras civiles, pero por lo menos las matanzas terminaron. La complejidad de la crisis colombiana, y su consiguiente efecto en la región andina, presenta un obstáculo insuperable, demasiado notable para ser solucionado solamente con la asistencia dirigida por Europa. Después del 20 de febrero, el objetivo urgente sigue siendo la mediación diplomática.

Una vez se reanude el proceso de paz, el papel líder de Europa, respaldado por la ayuda al desarrollo y recursos de inversiones, favorecidos por un clima más apropiado, les proporcionará a todos la base necesaria para convencer a las guerrillas a sentarse a la mesa de negociación, más allá de los ceses de fuego y zonas de despeje. Los hechos de enero de 2002 confirman estas tesis, dramatizada por la ruptura del 20 de febrero.

El segundo problema para la ejecución de la ayuda europea ha sido, antes y después del 20 de febrero, la carencia de seguridad impuesta no solo por las actividades

39. Véanse, entre otras evaluaciones, las conclusiones de la conferencia organizada por el Centro Norte-Sur en marzo de 2002.

40. Sergio Gómez MASERI. Informe de Clinton da garrote y zanahoria. El Tiempo, 27 de enero de 2001.

41. Combustible Colombia, Editorial, The New York Times, 28 de enero de 2001; EFE. Bush backs training Colombians. The Miami Herald, 27 de enero de 2001, p. 3 A. 
de la guerrilla (el ELN en una amplia zona reservada para los programas piloto de la UE; las FARC en el resto del país), sino también por la amenaza de los grupos paramilitares. Sin un adecuado clima de protección, las ONG's independientes poco pueden hacer para mejorar las condiciones en el terreno. Los observadores en Bruselas consideran que las organizaciones colombianas no tienen la capacidad gerencial para administrar las impresionantes cantidades anunciadas. Los precedentes históricos en ayuda humanitaria y destinada al desarrollo aconseja una cierta dosis de escepticismo acerca de la participación de agencias en el suministro de la ayuda debido a los retrasos en recibir los fondos y recursos, la competencia entre los diferentes grupos, su carencia de coordinación y la llamada «capacidad de absorción». «Buenas intenciones», como reza el título de un clásico análisis de la asistencia internacional, es la etiqueta adecuada, aplicable al saldo de la ayuda global a Colombia ${ }^{42}$.

A pesar de todas estas dificultades, los observadores optimistas consideran que la atmósfera de incertidumbre, alarma internacional, y la sensación de impotencia en obtener los resultados militares, finalmente, convencerán a los contendientes a negociar una paz duradera. Desde mediados de 2001 todos los esfuerzos de la comunidad internacional se han dirigido en esa dirección.

En todo momento, la Comisión Europea (reflejo de un sentir generalizado en Europa) se ha sentido optimista porque la ayuda está condicionada al respeto de los derechos humanos y se concentra en zonas críticas para esta labor ${ }^{43}$. Después de todo, «la esperanza es lo último que se pierde». Incluso con el éxito parcial de la precaria reanudación de las negociaciones, el 20 de enero de 2002, los europeos se sentían recompensados. Se espera que, en el caso de que algún día se reviva la tregua terminada el 20 de febrero, el papel de Europa volverá al centro del escenario. Por el momento, el reconocimiento del simple esfuerzo será la recompensa más apropiada ${ }^{44}$. Además de señalar las imperfecciones y limitaciones, este trabajo trata de hacer un mínimo de justicia a este esfuerzo europeo, cualquiera que sea el resultado final de la crisis colombiana. Los observadores internacionales consideran imposible la victoria militar de ninguna de las partes, con lo cual se devolverá el protagonismo a la comunidad internacional en su papel estelar de la negociación. La contribución europea será de esa manera debidamente reconocida.

42. Fernando CEPEDA. Más allá de las buenas intenciones. El Espectador, agosto de 2001. Véase el libro de Sherman Forman y Steward Patrick. Good Intentions: Pledges for Aid for Postconflict Recovery. Boulder: Lynne Rienner, 2000.

43. AFP. UE rechaza de plano la parte militar del Plan Colombia. Diario las Américas, 2 de febrero de 2001.

44. El papel de la comunidad internacional. El Tiempo, Bogotá, 21 de enero de 2002. 


\section{III.1. De persuasión y buena intención a contradicción y frustración}

Tras el final de la Guerra Fría y la desaparición de los subsidios soviéticos, la política cubana de cortejar las inversiones extranjeras a través de consorcios resultó en una notable corriente de inversiones europeas, sobre todo españolas, con gran visibilidad en sectores del turismo. La supervivencia del régimen cubano en el segundo lustro de la década de 1990 obligó a los Estados Unidos a adoptar medidas disuasorias de la inversión extranjera en Cuba. El resultado fue un abierto enfrentamiento entre los intereses europeos y Washington a causa de los aspectos extraterritoriales de las iniciativas legales norteamericanas como las Leyes Torricelli y Helms-Burton46.

Entretanto, lo que antaño se llamó Europa Occidental procedía a consolidar sus relaciones con el régimen cubano (con las condiciones de cada caso), como pretendiendo que Cuba tenía un sistema político normal según los lineamientos de la democracia liberal. Simultáneamente el proceso de integración de la UE había desarrollado sus procedimientos institucionales compartidos, anclados en el Estado de derecho. Celosos de la soberanía nacional, los Estados se habían reservado áreas sensibles de política exterior y mantenían actitudes autónomas hacia Cuba. En cada caso, velaban por sus propios intereses, pero la relación estaba inspirada en buenas intenciones ${ }^{47}$ (en la mejor tradición de la asistencia al desarrollo), y compartían un mínimo de consenso en el entramado institucional de la UE. El resultado ha sido una política que combina un notable grado de contradicción (incluso en clara violación de las reglas comunes) y una cierta confusión, con un perfil de cohesión y una estrategia basada en la persuasión. El resultado más visible era una serie de tácticas basadas en el uso de la «zanahoria», en contraste con el «garrote» empleado por los Estados Unidos. La UE como ente colectivo raramente ha cruzado la línea que separa su actitud del ejercicio de la presión. Sin embargo, en definitiva comparte una característica de la sensación de frustración experimentada por el gobierno español, un sentimiento también sufrido por el gobierno norteamericano, aunque convertido en irritación. Aunque la política de sistemática confrontación con los Estados Unidos no ha formado parte del guión de la UE, muchas de las acciones colectivas y de los Estados miembros se han diseñado y ejecutado como respuesta a las acciones de Washington, una potencia que está ausente del

45. Esta parte del artículo está basada en una ponencia presentada en la conferencia sobre Cuba: Integration into the international system, organizada por el Pell Center for International Relations and Public Policy, de la Universidad Salve Regina, Newport, Rhode Island, los días 22 a 24 de marzo de 2002. Mi agradecimiento reconoce la invitación de Richard Nuccio y Alberto Coll.

46. Para una revisión de las actitudes europeas antes de los acontecimientos de 1996 (derribo de las avionetas de «Hermanos al Rescate», aprobación de la Ley Helms-Burton y la Posición Común), véase IRELA. Cuba: Economic transformation and cooperation with the European Union. Madrid, 1995.

47. Para un clásico estudio sobre la asistencia internacional, véase Sherman Forman y Steward PATRICK. Good Intentions: Pledges for Aid for Postconflict Recovery. Boulder: Lynne Rienner, 2000. 
escenario cubano, el único terreno del planeta en que los intereses económicos de Europa no tienen que competir con los Estados Unidos. En suma, los europeos han tenido sus mejores éxitos al enfrentarse a Washington, en contraste con sus dificultades para diseñar una política cohesionada ante el régimen cubano48.

La actitud oficial de la UE hacia Cuba y su problemática relación con los Estados Unidos pueden ser resumidas por tres fragmentos de tres diferentes declaraciones: 1) condena las repetidas violaciones de los derechos humanos en Cuba, en particular en el terreno político, y considera que el embargo contra Cuba debe resolverse bilateralmente ${ }^{49}$; 2) se opone a las leyes extraterritoriales de los Estados Unidos que pretenden regular las actividades de personas bajo la jurisdicción de los Estados miembros de la UE, con lo que se viola el derecho internacional y afecta a los intereses de la UE50; y 3) si Cuba desea recibir un trato preferencial a través de un acuerdo de cooperación, debe presentar progresos en el proceso democrático ${ }^{51}$.

Sin embargo, las relaciones económicas y comerciales con Cuba se han desarrollado autónomamente de la política colectiva, independientemente de las limitaciones impuestas por los Estados Unidos, y frecuentemente como reacción a las medidas de Washington. Mientras diversos gobiernos europeos muestran una impresionante unidad al oponerse a la Ley Helms-Burton, el Reino Unido y España revelan actitudes diferentes según se trate de sus especiales relaciones con los Estados Unidos y Cuba. En ese contexto, el entramado institucional de la UE ha sido la fuente más reactiva y efectiva para oponerse a las Leyes norteamericanas, y al mismo tiempo forjar la maquinaria de un compromiso que evite el enfrentamiento comercial directo con serias consecuencias. Esa política de doble pinza (oposición a los Estados Unidos; condicionamiento de la ayuda a Cuba) ha sido consistente durante años.

\section{III.2. El fracaso del acuerdo de cooperación}

El derribo de las avionetas de «Hermanos al Rescate» el 23 de febrero de 1996, y la subsiguiente aprobación de la Ley Helms-Burton, forzó el freno de las negociaciones del acuerdo de cooperación entre Bruselas y La Habana. Estos dos acontecimientos cruciales formaron el contexto de las ulteriores medidas tomadas por la UE, la aprobación de la cláusula legal ante Helms-Burton, y la plasmación de la Posición Común ante Cuba, condicionante de acuerdos futuros.

48. Esta sección tiene su origen en la adaptación de fragmentos de mi libro titulado Cuba, the United States and the Helms-Burton Doctrine: international reactions. Gainesville: University Press of Florida, 2000, y artículos relacionados.

49. European Union, Explanation of Vote, United Nations General Assembly, New York, 26 de octubre de 1994.

50. Reglamento del Consejo, noviembre 1996.

51. Posición Común, 1996. 
El final abrupto de las negociaciones reveló que el camino arduo y difícil estaba condenado al fracaso. Todo comenzó a encarar la recta final cuando, según las recomendaciones de la Comisión Europea de 28 de junio de 1995, una delegación de la Troika (Francia, España, Italia) visitó La Habana entre el 6 y el 10 de noviembre. El Consejo Europeo, bajo Presidencia española, que tuvo lugar en Madrid, el 15 de diciembre de 1995, le encargó a la Comisión la misión de redactar un acuerdo de cooperación que estuviera listo el siguiente semestre. Con este fin, Manuel Marín, el comisario español y vicepresidente de la Comisión, visitó La Habana del 8 al 10 de febrero, y se reunió con Fidel Castro y otros líderes cubanos. Mientras abandonaba la capital cubana, el gobierno arrestaba a varios dirigentes de la disidencia y enviaba un claro mensaje de rechace de la petición de reforma de las políticas de derechos humanos. Unos días después, los Migs de la Fuerza Aérea destruían todos los planes de un acuerdo. Días después, se aprobó la Ley Helms-Burton.

Al tiempo que protestaban por la aprobación de esta ley, las instituciones europeas condenaron la acción contra las avionetas desarmadas. La atmósfera del grave incidente recibió una respuesta doble: el gobierno norteamericano reforzó las condiciones del embargo, y la UE puso el freno definitivo al acuerdo de cooperación. En cualquier caso, las posibilidades del acuerdo eran ya muy débiles debido a las condiciones presentadas por la UE. La reforma del Código penal y el reconocimiento de la oposición eran los requisitos básicos, un serio obstáculo para la aprobación cubana ${ }^{52}$. Castro lo consideró como una humillación y optó (como tiene por costumbre) por aprovechar la situación y adujo ser el blanco de acoso y conspiración internacional.

Esta carencia de entendimiento entre la UE y Cuba todavía es objeto de debate. Una corriente de opinión considera que el desdén demostrado por La Habana fue la gota que colmó el vaso de la paciencia de Bruselas. Manuel Marín, experimentado líder comunitario, demostró que trató hasta el último minuto y finalmente (en palabras de fuentes de la Comisión) «tiró la toalla». Otra interpretación es que a propósito elevó el listón de las exigencias de la $\mathrm{UE}^{53}$, y a sabiendas de que la dirigencia cubana era muy reticente, las condiciones europeas se endurecieron. Marín, según todos los indicios, estaba convencido de que podría tener éxito en obtener lo que tantos habían intentado por presión o persuasión, y al final se sintió engañado por lo que en algún momento interpretó como una actitud negociadora de Castro. El cambio inminente de gobierno en Madrid, como resultado de las elecciones legislativas, fue tanta coincidencia como el trueque de liderazgo en París. En ambos casos se trataba de la transición de un gobierno socialista a uno conservador.

52. Ángel ViÑAS. La Unión Europea y Cuba: Historia de una acción de estrategia exterior en la posguerra fría. En Teodoro Flores GómEZ (ed.). Temas de economía internacional: Volumen de homenaje a Rafael de Juan y Peñalosa. Bilbao: Universidad del País Vasco, 1996, pp. 311-359.

53. Richard NUCCIO (asesor especial del presidente Bill Clinton) culpó de este hecho a Castro en un artículo publicado en The Angeles Times, 17 de enero de 1998, distribuido en otros medios (véase, por ejemplo, Es Castro quien aísla al país. El Nuevo Herald, 22 de enero de 1998). 
En términos estratégicos, el proyecto fracasó porque fue interpretado como una oferta hecha en coalición con los Estados Unidos, algo que Castro no estaba dispuesto en absoluto a aceptar ${ }^{54}$. A pesar de que la sintonía entre Bruselas y Washington entonces era notable, y se habían efectuado numerosas consultas cuidadosas entre los responsables de la política cubana de los Estados Unidos, España, Italia y Francia, no se tenía pública constancia de un pacto entre Europa y los Estados Unidos, pero el gobierno cubano sospechaba que se estaba tramando cierta cooperación. Lo cierto es que Marín había estado en contacto cerrado con el gobierno español todavía presidido por Felipe González, y creyó que había alguna oportunidad. El fracaso dejó un trauma indeleble en la bienintencionada agenda de Marín, quien luego decidió mantenerse al margen de nuevos intentos ${ }^{55}$. Con el cierre de la «opción latinoamericana» de un acuerdo de cooperación, quedaba solamente la alternativa del acceso a la Convención de Lomé. Esta opción («por la puerta trasera», según la expresión usada por los cínicos observadores) sería seriamente explorada por el gobierno cubano.

Cuando el proyecto de acuerdo fracasó, la segunda respuesta de dureza de Bruselas llegaría como el suplemento de la crítica a Helms-Burton. Mientras la medida antídoto contra Helms-Burton (por la que se prohibía a los Estados miembros que se plegaran a las exigencias de los Estados Unidos, y se ofreciera protección ante los daños sufridos) era una novedad en las decisiones de la UE, una Posición Común sobre Cuba, tomada por primera vez sobre un país latinoamericano, llenaría un espacio en los anales de la incipiente política exterior de los Estados Unidos ${ }^{56}$. El espíritu y la letra de la Posición Común se han mantenido desde entonces, con la consabida protesta del gobierno cubano. La renovación de esta Posición tuvo lugar en el Consejo de Ministros celebrado en Bruselas el 9 de diciembre de 199757, y fue confirmada en mayo de 1998 durante la firma de la tregua entre los Estados Unidos y la UE.

\section{III.3. La reprimenda a Cuba: la Posición Común}

El 2 de diciembre de 1996, el poderoso Consejo de Ministros de Economía y Finanzas (ECOFIN) aprobó la Posición Común sobre Cuba. Su objetivo era alentar el proceso de transición hacia una democracia pluralista y de respeto de los derechos

54. Véase el trabajo de Richard NuCcio. Cuba: A U.S. Perspective. Presentado en la conferencia Transatlantic Tensions: The Challenge of Difficult Countries. Washington, D.C.: Brookings Institution, March 9-10, 1998. En Richard N. HAASS (ed.). Transatlantic Tension: The United States, Europe, and Problem Countries. Washington, D.C.: Brookings Institution, 1999, pp. 7-28.

55. De fuentes de la Comisión.

56. Para una revision detallada de estos hechos: IRELA. Cuba y la Unión Europea: Las dificultades del diálogo, 17de junio de 1996.

57. EFE. Firme la UE frente a Cuba. Diario las Américas, 9 de diciembre de 1997. 
humanos ${ }^{58}$. Normalmente, tal acción hubiera quedado enterrada entre los cientos de documentos aprobados por las instituciones de la UE. Era, por el contrario, una novedad, por multitud de razones. En primer lugar, tenía a Cuba como objetivo, el centro de la controversia causada por la Ley Helms-Burton. En segundo lugar, la medida fue aprobada justamente cuando la UE había también emitido un Reglamento y una Acción Común para oponerse a la legislación norteamericana. En tercer término, era la primera vez que tal medida se aplicaba a un país latinoamericano, específicamente al único que todavía no disfruta de un acuerdo de cooperación. Finalmente, era la primera de tales acciones ejecutadas por la nueva Política Exterior y de Seguridad Común (PESC). Sin embargo, la Posición Común no tenía mayores novedades, ya que era la confirmación de una política repetitiva. Pero, debido a que tales medidas son de obligado cumplimiento para los Estados miembros, se debe admitir que la UE también había codificado su política exterior hacia Cuba de forma similar a Helms-Burton. Sin embargo, en contraste con la política de los Estados Unidos, la UE declaraba que quería continuar el diálogo con Cuba 59 .

La Posición Común es rastreable a la Resolución del Parlamento Europeo de 1993, un documento de la Comisión Europea de 28 de junio de 1995, y la petición del Consejo Europeo de 15-16 de diciembre. Cuando las negociaciones cesaron como resultado del incidente de las avionetas y la aprobación de Helms-Burton, el nuevo gobierno español presentó el proyecto inicial el 14 de noviembre, y fue examinado por el Comité Político del Consejo de la UE el 25 de noviembre. Algunos miembros consideraron que el lenguaje era demasiado cercano al empleado por los Estados Unidos. Mientras el Reino Unido aparecía aliado con España, la mayoría de los países influyentes (Alemania, Bélgica, Francia, Italia y los Países Bajos) pidieron cambios. Se rechazó el nombramiento de un representante de cada embajada en La Habana para contactar a la disidencia, la cooperación con el rapporteur de la ONU para Cuba, y la demanda de que se permitieran viajar a todos los cubanos ${ }^{60}$. El documento final quedó reducido a unos temas fundamentales.

En primer lugar, la UE declara que desea alentar una transición pacífica en Cuba hacia la democracia pluralista. La UE prefiere que esto suceda a iniciativa del gobierno cubano, no mediante coerción del exterior. En segundo lugar, si Cuba desea recibir un trato favorable mediante un acuerdo de cooperación, debe mostrar progresos en el proceso democrático, reflejado en informes semestrales sometidos por la Comisión al Consejo. Estos informes incluirán el respeto de los derechos humanos, la liberación de presos políticos, la reforma del código criminal, y el cese del hostigamiento de los disidentes. En tercer lugar, la UE quiere mantener el diálogo no solamente con el gobierno

58. Para un examen detallado de la evolución de esta medida: IRELA. The EU's Common Position on Cuba.

59. Juan TAmayo. Europeans Get Tough in Policy on Cuba. The Miami Herald, 3 de diciembre de 1996.

60. IRELA. The EU's Common Position on Cuba, 13 de diciembre de 1996. 
cubano sino con todos los sectores de la sociedad. Cuarto, por otro lado, la UE reconoce el progreso hecho en las reformas económicas y está dispuesta a ofrecer cooperación en este terreno a través de los Estados miembros. Finalmente, la ayuda humanitaria continuará a través de las apropiadas ONG's ${ }^{61}$. La Posición Común se insertó en los anales de la incipiente PESC $^{62}$.

Cuba reclama que el origen de la Posición está íntimamente ligado a la visita de $\mathrm{Al}$ Gore a Madrid el 25 de mayo, al anuncio de la terminación de la ayuda humanitaria a Cuba, los vínculos entre Aznar y la Fundación Cubano-Americana y el establecimiento de una Fundación Hispano-Cubana en Madrid63. En cualquier caso, la Posición de la UE ha dominado el contexto de las también fallidas negociaciones para el ingreso de Cuba en la Convención de Lomé, con el resultado del abandono del proceso por parte del gobierno cubano en abril de 2000. Para la mayoría de los observadores ${ }^{64}$, la percepción de La Habana era que el alto precio político a pagar (requisitos políticos, especialmente en el área de derechos humanos) no ameritaba los beneficios económicos.

Comprensiblemente, estas condiciones no fueron aceptadas por el gobierno cubano, ya que contrastan con la ausencia de mínimos requisitos en otros casos, como Marruecos, Israel y Guatemala, y el hecho de que la UE está implementando una unión aduanera con Turquía (a la que se deniega su ingreso en la UE) y ha firmado cuatro acuerdos de cooperación con China, acusada de violación de derechos humanos ${ }^{65}$. Cuba respondió que su conducta política no estaría sujeta a los términos de los informes de la UE. España se convirtió en blanco de las represalias de Cuba, como la retirada del placet para el nuevo embajador, lo cual desencadenó una de las crisis más graves entre los dos países justamente cuando se preparaba la conmemoración del centenario de 1898. En contraste, la Posición Común satisfizo al Departamento de Estado norteamericano ${ }^{66}$, con la expectativa en Bruselas de recibir una muestra de reciprocidad en forma de gesto norteamericano hacia la UE.

A pesar de la fricción, en cumplimiento con los términos de la Posición Común, la UE ha mantenido la ayuda humanitaria a través de programas administrados por ECHO. Por su parte, Cuba ha adoptado el euro, la moneda común europea ${ }^{67}$. Las autoridades cubanas favorecen el uso de la nueva moneda porque reduce el poder del dólar ${ }^{68}$ y porque el 50\% del turismo en Cuba procede de Europa y el 44\% del comercio se hace con la UE.

61. IRELA. The EU's Common Position, pp. 2-3. 1996.

62. IRELA. Cuba y la Unión Europea: Las dificultades del diálogo. Madrid: IRELA, 17 de junio de

63. IRELA. The Common Position, p. 4.

64. Entrevistas llevadas a cabo en Bruselas y Madrid durante los meses de junio y julio de 2000 y 2001.

65. Perera GÓmez. Ibíd., p. 113.

66. State Department Communiqué, 3 de diciembre de 1996.

67. El euro compite con el dólar en los centros de turismo: Reuters. El euro desafía al dólar en Varadero. El Nuevo Herald, 25 de mayo de 2002. 1999.

68. EFE. Banco de Cuba, con grandes expectativas ante el euro. El Nuevo Herald, 1 de enero de 


\section{III.4. Perfil nacional ${ }^{69}$}

La variación parece ser la orden del día con respecto a las actitudes europeas sobre Cuba, lo cual explica la carencia de una política coherente y bien coordinada. Mientras Bélgica puede ser considerse como observador neutral, más crítico cuando está gobernado por conservadores que por socialdemócratas, los gobiernos críticos están liderados por el llamado «fundamentalismo nórdico» de Suecia basado en presiones sobre los derechos humanos. Alemania ha optado por un reacomodo gradual y el Reino Unido se inclina con reservas hacia en trato basado en el comercio. La relación especial entre España y Cuba ha neutralizado parte de la actitud dura de José María Aznar tras su llegada al poder en 1996. Italia ha replicado la política de engagement de Francia, mientras Portugal ha tratado de insertar a Cuba en su política latinoamericana. De los países europeos que son miembros de la UE, solamente Finlandia no mantiene una embajada en La Habana (por razones económicas)70.

Un retrato aproximado de las actitudes de los diferentes Estados miembros de la UE sobre Cuba incluye un bloque sureño compuesto por España, Portugal, Italia y Francia que actúan como principales aliados políticos y económicos. En contraste, Alemania, el Reino Unido y Suecia se distancian en la dimensión política. Con menos influencia en los asuntos mundiales, Austria, Bélgica y Finlandia no tienen intereses especiales en el Caribe y Latinoamérica. Un grupo de «bloqueadores» (Finlandia, Holanda, Suecia y el Reino Unido) parecen liderar el freno del proceso a un acuerdo post-Lomé, mientras los «aperturistas» (Francia, Portugal, España e Italia) favorecen una actitud positiva. Los «mediadores» (Austria, Bélgica y Alemania) están prestos para actuar según las circunstancias ${ }^{71}$. Los observadores han notado que la Posición Común no tiene vigencia a la vista del volumen de las relaciones bilaterales de los Estados más importantes. Está siendo violada por España, el socio más importante de Cuba en términos de comercio y ayuda, tanto con gobiernos socialistas o conservadores. Solamente los países nórdicos respetan los términos de la posición. Sarcásticamente, algunos observadores dicen que la Posición Común no es ni posición, ni común.

III.5. ACP: ¿la puerta trasera a la UE?

La búsqueda de la ubicación de Cuba en el entramado de la UE a través de las páginas digitales de Bruselas es un ejercicio frustrante porque no parece tener un lugar

69. Esta sección refleja el contenido de un artículo de Susanne GRATIUS, titulado Cuba: un caso aparte en la política exterior de la Unión Europea, publicado como capítulo en el libro titulado, Joaquín Roy y Roberto Domínguez (eds.). Las relaciones exteriores de la Unión Europea. Mexico: UNAM, 2000 .

70. IRELA. Revision of European Policy on Cuba, pp. 17-21.

71. IRELA. Revision of European Policy on Cuba, p. 1. 
preciso, al ser el único país latinoamericano que no cuenta con un acuerdo de cooperación y no disfruta de un espacio concreto en el organigrama de los funcionarios de la Dirección de Desarrollo. Cuando se produjo el fracaso de la petición a los acuerdos post-Lomé, los funcionarios que trataban el dossier de Cuba bromeaban que estaban a cargo de «los ACP... y Cuba», sin documentos, mientras todos los archivos estaban congelados en la Dirección de Relaciones Exteriores, y la delegación de México estaban acreditada teóricamente también en La Habana. Esta anomalía se complicó todavía más cuando Cuba ingresó como miembro en los ACP, pero sin firmar el acuerdo de Cotonou, sucesor de Lomé.

La senda hacia el acuerdo post-Lomé se inició en Bruselas en septiembre de 199872 y culminó con la firma el 23 junio de 2000. Desde entonces, La Habana no debería tratar con una oficina en Bruselas sino con una red de 77 países, relacionados con otros 15 de la UE. Sin embargo, Castro rechazó el procedimiento y adujo que la Resolución de la Comisión de Derechos Humanos era discriminatoria, y suspendió la visita de la Troika ${ }^{73}$. Irónicamente, el clima de la membresía de Cuba era positivo y había oscilado hacia la normalización de la relación entre la UE y Cuba, esta vez anclada en el contexto multilateral de los ACP74. Solamente algunos gobiernos europeos se oponían, liderados por el Reino Unido, Holanda y Suecia. Londres aparentemente había amenazado con vetar el acuerdo cuando llegara al Consejo. Cuba había calificado las condiciones de la UE como «arrogantes», «inaceptables», y «dependientes de la política de los Estados Unidos» ${ }^{75}$. Los que apoyaban la membresía de Cuba consideraron la reacción cubana como sorpresiva y violenta. De hecho, fue una bofetada en la cara de los países que habían abogado por el ingreso de Cuba. Diplomáticos de países ACP en Bruselas confesaban públicamente que estaban sorprendidos, pero los más experimentados confidencialmente habían sospechado la decisión, que no les tomó con la guardia bajada ${ }^{76}$. Los funcionarios de la UE cínicamente expresaban satisfacción por lo que temían había sido el resultado de un duro trabajo y grandes esperanzas. La evidencia muestra que la decisión fue el resultado de un largo debate interno en Cuba acerca de los costos y los beneficios. El gobierno cubano había calculado que los beneficios no eran la compensación adecuada por la pérdida de la independencia política y la inserción en un entramado multilateral de consecuencias impredecibles sobre democracia y derechos humanos. En una reunión de altos dirigentes del Caribe y Centroamérica, Castro calificó el trato como «demasiado fastidio para tan poca plata» ${ }^{77}$.

72. Francesc GRANELL, Cuba y la Unión Europea: del encuadre latinoamericano al ACP caribeño. Revista Española de Desarrollo y Cooperación, 1998, n. ${ }^{\circ} 3$.

73. Resolución sobre Cuba presentada por Polonia y la República Checa.

74. IRELA. Revision of the European Policy towards Cuba: Perceptions and Interests of the EU Member States, Madrid, 2000.

75. Granma, 29 abril de 2000.

76. Entrevistas en Bruselas y el Caribe durante los meses de julio y agosto de 2000 .

77. Cita textual de un alto dirigente caribeño. 
En la continuación de este mini-drama, algunos meses después, el 14 de diciembre de 2000, Cuba se convirtió en el 78 miembro del grupo ACP. La peculiaridad de este acontecimiento es que Cuba ingresó en los ACP sin firmar el acuerdo de Cotonou ${ }^{78}$. Esta anomalía puede hacer creer que Cuba ha conseguido los beneficios de rigor. La carta de esta organización tuvo que ser enmendada para acomodar el ingreso de un nuevo miembro que no gozará del único servicio: el trato preferencial en comercio y cooperación por parte de la UE. En términos comparativos, sería como pertenecer a un exclusivo club de golf, pero sin poder practicar ese deporte y limitarse a pasearse por las instalaciones y ver cómo otros socios golpean la pelota por los hoyos ${ }^{79}$. Los observadores experimentados apuntan que éste es un ejemplo más del clásico compromiso de la UE para dar a los tres protagonistas (los países miembros, los ACP y Cuba) la impresión de que han ganado algo en la preparación del ingreso de Cuba algún día.

\section{III.6. Sintomas actuales}

Los movimientos diplomáticos muestran cierto grado de ambivalencia y contradicción según las circunstancias reinantes, quién detenta la Presidencia y qué clase de conflictos y prioridades afectan a los Estados miembros. Por ejemplo, en un intento más para acelerar la profundización de la relación entre Cuba y la UE, el viceprimer ministro belga, y ministro de Asuntos Exteriores, Louis Michel, quien detentaba la Presidencia de la UE, visitó La Habana en agosto de 2001, con lo que reavivó las expectativas en Europa y la preocupación en Washington. El gobierno cubano consideró la visita a nivel binacional, mientras España rebajó su representación al mínimo. La visita solamente fue anunciada a la Comisión con cinco días de anticipación en plenas vacaciones veraniegas, sirvió para suavizar la fricción entre Bruselas y La Habana causada por la votación en Ginebra. La UE quería mandar un mensaje de mantener la puerta abierta y el gobierno cubano consiguió mostrar que contaba con Bruselas, especialmente durante la Presidencia belga. Esta relación sería más difícil durante la presidencia española el siguiente semestre, cuando el gobierno español estaría mucho más ocupado en temas más urgentes 80 .

En cuanto a la asistencia humanitaria, los fondos de la UE proporcionados por la Comisión han aumentado considerablemente en el último lustro: de 0,6 millones de euros en 1997 a 5,4 en 2001, con un máximo de 8,2 en 2000. El canal preferido son las ONG's para ayudar a la incipiente sociedad civil81. Desde 1993, la UE ha financiado casi

78. Véase la declaración en la página web: http://www.acpsec.org/gb/press/146b034e.html.

79. Georgetown Agreement de 1992.

80. Véase mi columna titulada Cuba y la Unión Europea. Diario 16, 5 de septiembre de 2001.

81. De fuentes de la Comisión. 
125 millones de $€$ en asistencia, de los que casi dos tercios pertenecen a la ayuda humanitaria.

Se espera que entre 15 y 18 millones de $€$ se destinen anualmente a los programas medioambiantales ${ }^{82}$. Las catástrofes naturales como el huracán Michelle son la justificación de esta ayuda especial, teniendo en cuenta las consecuencias económicas. El impacto negativo de los ataques del 11 de septiembre en el turismo, el descenso consiguiente de las remesas procedentes de los Estados Unidos, y la desaparición de los subsidios rusos por la base de Lourdes, son otros factores. En este contexto, la integración regional en su hábitat natural es la única alternativa para Cuba. En consecuencia, la Comisión Europea favorece la integración regional de Cuba en el Caribe, Latinoamérica y los ACP, y muy especialmente la participación en CARIFORUM (el mecanismo de canalización de la ayuda europea en el Caribe, del cual Cuba es miembro desde octubre de 2001).

Más complejo es el panorama de las consecuencias del impasse de la solicitud de Cotonou. Como continuación de la novena evaluación de la Posición Común efectuada por el Consejo el 25 de junio de 2001, la UE declaró que abogaba por un diálogo con Cuba que desembocara en un acuerdo de cooperación basado en el respeto de los derechos humanos y el Estado de derecho. Esta conclusión fue reiterada por el Consejo en la décima evaluación de 10 de diciembre de 2001, en la que se confirmó la vigencia del artículo 9 del acuerdo. Teniendo en cuenta que Cuba no ha presentado su solicitud de ingreso, la UE no toma ninguna decisión. Una vez lo haga, los órganos competentes según el artículo 94 deberán examinar las credenciales ${ }^{83}$.

Sin embargo, en el caso del ingreso de Cuba como miembro, todavía se debería examinar si gozará de los mismos beneficios que el resto, ya que los 77 miembros reciben sus beneficios según unos programas indicativos estipulados para el presente período. La alternativa sería una línea especial otorgada por la Comisión, como se hizo en el caso de Sudáfrica. Una vez se produjera el ingreso de Cuba, debería cumplir con los requisitos del adquis (como en el caso de membresía en la UE) de Cotonou ${ }^{84}$.

En este contexto, habrá que tener en cuenta la actitud de los países miembros individuales ya que, según algunos, Cuba no ha hecho progreso alguno en el terreno de los derechos humanos, y por lo tanto deberá ser juzgada por el mismo rasero que requiere el artículo 94. En contraste con la votación de Ginebra, o los términos sujetos de la Posición Común (que son dictados por una decisión unilateral de la UE o sus Estados miembros), los beneficios de Cotonou están estipulados por un acuerdo multilateral sujeto al Derecho internacional. En cualquier caso, revelaría una evidente incoherencia que los mismos Estados que en Ginebra votan consistentemente con la censura de Cuba, luego aprobaran las credenciales presentadas para el acuerdo de Cotonou.

Naturalmente, este nuevo escenario tiene que tener en cuenta dos actores más. El primero es, por supuesto, el propio gobierno cubano, siempre listo a seguir la senda

82. Datos y consideraciones de fuentes de la Comisión.

83. Fuentes de la Comisión.

84. Fuentes de la Comisión. 
más imprevista, tal como acertadamente describe Michael Erisman ${ }^{85}$. De todas maneras, el espacio de maniobra se ha empequeñecido con las disputas con México y Uruguay, precisamente como resultado de las decisiones de Ginebra. El segundo es el vecindario del Caribe (respaldado por Europa) que considera que una súbita desestabilización de Cuba no favorecería el interés general. Las señales recientes apuntan a que la actividad internacional de Cuba se ha concentrado en el continente americano y sus preocupaciones se han alejado de Europa, a la que se percibe más atenta a los temas urgentes como la ampliación de la UE, el ascenso de la ultraderecha y la inmigración. Esta tesis estaría confirmada por la ausencia de Castro en la II Cumbre UE-Latinoamérica-Caribe celebrada en Madrid los días 17 y 18 de mayo de 2002, decisión que replicaba la inasistencia a la Cumbre Iberoamericana de Lima en 2001, un acontecimiento anual en el que el líder cubano ha sido siempre el protagonista principal de sonadas polémicas ${ }^{86}$. De entre las razones que justifican su decisión está su cálculo de no recibir los beneficios apetecidos y arriesgar una confrontación con sus colegas, muy especialmente el presidente español José María Aznar.

Sigue abierta a la conjetura si una activación del título III de Helms-Burton provocaría una reacción de la UE hasta el extremo de hacer peligrar el futuro de la Organización Mundial del Comercio (OMC), que está agobiada por litigación de índole política, lo que se trató de evitar con los entendimientos de 1997 y 1998. Pero toda esta lógica pertenece a la escena anterior al 11 de septiembre. Desde ese día, todo es tan predecible como inimaginable. Desde la caída del Muro de Berlín, «el futuro ya no es lo que era», pero ahora es menos predecible todavía. El futuro de Cuba y, por lo tanto, la actitud europea, están sujetos a demasiadas variables.

A pesar de todo, en el caso (más que probable) de que la relación entre los Estados Unidos y Cuba continúe como está mientras sigue la inexorable transición por condicionamientos biológicos, se espera que la actitud europea no cambiará. La UE como entidad colectiva seguirá actuando con una mezcla de contradicción y coherencia, mediante la condicionalidad de la ayuda bilateral, y el mantenimiento de la Posición Común se reducirá a un endoso de esa política. El grueso de la ayuda disponible se dedicará al anclaje mínimo de Cuba en la economía de mercado ${ }^{87}$. Al mismo tiempo, un sentido de moderada frustración, combinada con cierta resignación, será el común denominador de la actitud europea. Esta percepción subsistirá en el caso de que la situación interna de Cuba no empeore más allá de los límites tolerables. En la eventualidad de que durante la definitiva transición cubana, la política europea dé los

85. Cuba's Foreign Relations in a Post-Soviet World. Gainesville: University Press of Florida, 2000.

86. Peru Egurbide. Fidel Castro pide visado. El País, 15 de mayo de 2002; Pablo Alfonso. Castro decide no asistir. El Nuevo Herald, 17 de mayo de 2002.

87. Confirmado en un encuentro entre el comisario Poul Nielson y el vicepresidente y ministro de Cooperación Internacional, Rodrigo Malmierca (Agence France Press, Europa ayudará a la economía de mercado. El Nuevo Herald, 5 de marzo de 2002, p. 17A). 
resultados apetecidos, el sentimiento de satisfacción será bien visible. Entretanto, cada uno de los Estados miembros procederá a defender sus propios intereses y obligaciones históricas. La frustración disminuirá en la medida que se prime la disminución de las tensiones en la preparación de la transición pacífica, con el entendimiento de que el futuro de Cuba está, después de todo, en manos de los cubanos.

\section{CONCLUSIÓN COMPARATIVA}

La revisión de los hechos relacionados con la actitud de la UE ante Cuba y Colombia, y las correspondientes percepciones entre estos dos países latinoamericanos y Europa revela algunos detalles sumamente interesantes con respecto no solamente a la situación internacional de estos dos estados que encaran crisis notables, sino también acerca de la incipiente política exterior de la UE88.

En primer lugar, destaca la cierta cohesión europea que no revela grietas notables en su política hacia América Latina. En segundo lugar, la cohesión es mayor cuando el eje de una concreta decisión o pauta es enfrentarse a lo que se considera en Bruselas o en las principales capitales europeas como una política errónea de los Estados Unidos, y sobre todo cuando se percibe como perjudicial para los intereses colectivos de la UE o de alguno de sus Estados miembros. En el caso de Colombia, el anclaje del acuerdo europeo es su distanciamiento del Plan Colombia, considerado en su dimensión militar y de lucha contrainsurgencia. En el caso de Cuba, la unanimidad europea es evidente con respecto a su oposición frontal a la Ley Helms-Burton, y otras medidas unilaterales con efectos extraterritoriales. Esta impresión de política común está legalmente anclada en la obligatoriedad del cumplimiento de los tratados en materias enteramente insertadas en el mercado único. Por eso las medidas norteamericanas para disuadir el flujo comercial y de inversiones con Cuba colisionan frontalmente con la UE y han recibido respuestas contundentes. La naturaleza conservadora o izquierdista de los gobiernos europeos no constituye una diferencia en este terreno.

En segundo término, cuando los intereses nacionales (especialmente, políticos) recuperan el control de las decisiones colectivas, la cohesión de la UE sufre un cierto debilitamiento y revela la imperfecta arquitectura de la organización en materia de relaciones exteriores. Por razones históricas (como es el caso de España), combinadas con intereses comerciales o responsabilidad ética, la actitud de algunos países europeos se entromete en el cumplimiento cabal de la Posición Común impuesta a Cuba y en la plasmación de una coherente visión de la naturaleza de los grupos armados en Colombia. Las reticencias de algunos gobiernos, y las evidentes diferencias de opinión en el Parlamento Europeo, sirven de freno para la ejecución de una política coherente y

88. Para una visión comparativa: Joaquín Roy. La UE ante Cuba y Colombia. El Nuevo Herald, 10 de mayo de 2002. 
efectiva más allá de las promesas de ayuda económica y las labores de mediación ante las organizaciones guerrilleras 89 .

En el otro lado de la escena, la percepción que los gobiernos latinoamericanos tienen de la labor de la UE o sus Estados miembros no constituye un bloque homogéneo, como resulta evidente al comparar la energía con que algunos gobiernos centroamericanos han buscado la ayuda económica europea y han estado dispuestos a aceptar la política, con la reticencia de México hasta muy recientemente. Al comparar el caso de Cuba con el de Colombia, resulta evidente que el colombiano ha estado más dispuesto que el cubano a aceptar una serie de condicionamientos con tal de conseguir el apoyo europeo. Quizá por este motivo ha ido consiguiendo un apoyo político y escalonado, de acuerdo con su capacidad de cabildeo y la receptibilidad de los gobiernos europeos. En el contexto de la II Cumbre EU-Latinoamérica-Caribe, el presidente Pastrana obtuvo un claro apoyo de Aznar para presionar a sus colegas de la UE para incluir a las FARC en la lista de terroristas ${ }^{90}$.

De todas maneras, esta voluntad de cohesión y consenso no consiguió borrar enteramente la aparente contradicción interna de las expresiones usadas por los distintos protagonistas de la acción exterior de la UE. Tras la elección de Álvaro Uribe como presidente de Colombia, el 26 de mayo de 2002, la ambivalencia de los diferentes actores ante las FARC siguió siendo evidente, como predicción de cierta flexibilidad de acuerdo con los objetivos futuros. Mientras una delegación del Parlamento Europeo que visitaba Colombia para observar las elecciones, calificó la atmósfera como una presidida por «violencia, miedo, intimidación y coerción», los culpables eran considerados como «movimientos insurgentes»91. Mientras Javier Solana, Alto Representante de la Política Exterior y de Seguridad Común, expresaba admiración por el proceso democrático, a pesar de la campaña de «amenazas, intimidación y asesinatos»92, y Josep Piqué, ministro de Asuntos Exteriores de España (que presidía la UE), reconocía la dificultad de las condiciones bajo «muy serias amenazas de violencia»93, la Comisión felicitaba al nuevo presidente por buscar el diálogo con los «grupos armados»\$4. La etiqueta de «terrorista» había desaparecido de las declaraciones de los principales protagonistas de la implicación europea, con lo que se mantenía abierta la puerta a un nuevo contexto de negociaciones, según las pautas presentadas por el nuevo mandatario, y el hecho adicional de la ruptura del proceso de paz con el ELN ejecutada por Pastrana.

89. Joaquín Roy. Colombia y la UE: buenas intenciones. La Opinión de los Ángeles, 12 de marzo de 2002; Europa y Colombia. La Opinión de los Ángeles, 9 de mayo de 2002.

90. Cristina SEN. Los Quince otorgan a Pastrana un balón de oxígeno. La Vanguardia, 18 mayo de 2002, p. 4; Bosco EsTERUELAS. Aznar pide que la guerrilla colombiana figure entre los grupos terroristas de la UE. El País, 17 de mayo de 2002, p. 2.

91. Comunicado de prensa de la delegación de observadores del Parlamento Europeo, Bogotá, 26 de mayo de 2002

92. Declaración de D. Javier Solana, 27 de mayo de 2002.

93. Piqué felicita al ganador de las elecciones, Madrid, 27 de mayo de 2002.

94. Declaración, 27 de mayo de 2002. 
En contraste a la cierta sintonía entre los mandatarios colombianos y la UE, Cuba se resiste y no parece querer cruzar una barrera que considera innegociable cuando se menciona el terreno sensible de los derechos humanos. El precio político del apoyo europeo no parece equilibrar el aparente bajo nivel de los beneficios económicos de la membresía en el entramado post-Lomé. Es en este terreno donde también se observa una cierta intransigencia europea al no poder transgredir la letra de las regulaciones. Esta posición es en cierta manera coherente con la política general hacia Latinoamérica (como lo prueba la suspensión de la ayuda a Haití en los momentos de inestabilidad política) y la aplicación virtual de las cláusulas democráticas. La actitud ante Colombia es más respetuosa al reconocer las credenciales democráticas del sistema político colombiano y deber ser respetuoso de las pautas expresadas por el gobierno, sobre todo al haber estado negociando con la guerrilla. Cuba parece mostrar una extrema reticencia hacia el entramado multilateral de la UE, donde las actitudes de los países miembros pueden quedar más anónimas y no sujetas a condicionamientos históricos o culturales. Una cierta táctica de «divide y vencerás» es la preferida por Castro. Los diversos gobiernos europeos se refugian en las decisiones colectivas (Posición Común), pero resuelven usar su autonomía en materias soberanas cuando conviene.

En el terreno práctico, en conclusión, ambos casos de actividad europea en Latinoamérica revelan una semejanza en cuanto a la impresión de la UE y sus Estados miembros y los resultados conseguidos. De grandes esperanzas (en superar la política norteamericana) y buenas intenciones (en cumplir los parámetros de la asistencia internacional) se ha desembocado paulatinamente en una sensación de cierta frustración, al tiempo que los métodos para conseguir los resultados apetecidos aparecen lastrados por numerosas contradicciones y confusiones internas. Teniendo en cuenta las limitaciones del entramado legal de la UE en materia de relaciones exteriores, los logros parecen superar a las carencias.

\section{BiBLIOGRAFÍA}

ERISMAN, Michael. Cuba's Foreign Relations in a Post-Soviet World. Gainesville: University Press of Florida, 2000.

Forman, Sherman y PATrick, Steward. Good Intentions: Pledges for Aid for Posconflict Recovery. Boulder: Lynne Rienner, 2000.

GranelL, Francesc. Cuba y la Unión Europea: del encuadre latinoamericano al ACP caribeño. Revista Española de Desarrollo y Cooperación, 1998, n. ${ }^{\circ} 3$.

Gratius, Susanne. Cuba: un caso aparte en la política exterior de la Unión Europea. En RoY, Joaquín y Domínguez, Roberto (eds.). Las relaciones exteriores de la Unión Europea. MéxiCO: UNAM, 2000.

Nuccio, Richard. Cuba: A U.S. Perspective. Trabajo presentado en la conferencia Trasantlantic Tensions: The Challenge of Difficult Contraes. Washington, D.C.: Brookings Institution en 
marzo de 1998. En HASs, Richard N. (ed.). Trasantlantic Tension: The United States, Europe, and Problem Countries. Washington, D.C.: Brookings Institution, 1999, pp. 7-28.

Roy, Joaquín. Cuba, the United States and the Helms-Burton Doctrine: international reactions. Gainesville: University Press of Florida, 2000.

VIÑAs, Ángel. La Unión Europea y Cuba: Historia de una acción de estrategia exterior en la posguerra fría. En FloRES GómEZ (ed.). Temas de economía internacional: Volumen de bomenaje a Rafael de Juan y Peñalosa. Bilbao: Universidad del País Vasco, 1996, pp. 311-359. 